Review Article

\title{
Naturally Self-Assembled Nanosystems and Their Templated Structures for Photonic Applications
}

\author{
K. Pradeesh, Nageswara Rao Kotla, Shahab Ahmad, \\ Vindesh K. Dwivedi, and G. Vijaya Prakash \\ Nanophotonics Lab, Department of Physics, Indian Institute of Technology Delhi, Hauz Khas, New Delhi 110016, India \\ Correspondence should be addressed to G. Vijaya Prakash; prakash@physics.iitd.ac.in
}

Received 25 January 2013; Accepted 24 February 2013

Academic Editor: Amir Kajbafvala

Copyright (c) $2013 \mathrm{~K}$. Pradeesh et al. This is an open access article distributed under the Creative Commons Attribution License, which permits unrestricted use, distribution, and reproduction in any medium, provided the original work is properly cited.

\begin{abstract}
Self-assembly has the advantage of fabricating structures of complex functionalities, from molecular levels to as big as macroscopic levels. Natural self-assembly involves self-aggregation of one or more materials (organic and/or inorganic) into desired structures while templated self-assembly involves interstitial space filling of diverse nature entities into self-assembled ordered/disordered templates (both from molecular to macro levels). These artificial and engineered new-generation materials offer many advantages over their individual counterparts. This paper reviews and explores the advantages of such naturally self-assembled hybrid molecular level systems and template-assisted macro-/microstructures targeting simple and low-cost device-oriented fabrication techniques, structural flexibility, and a wide range of photonic applications.
\end{abstract}

\section{Introduction}

Fabrication of nano/mesa photonic architectures from topdown technology involve precise growth techniques like molecular beam epitaxy (MBE), chemical vapor deposition (CVD) and also involve patterning techniques such as photolithography, particle beam lithography, scanning probe lithography, and nanoimprint lithography. While the above mentioned processes are laborious, time-consuming, and costly, the "bottom-up" technology based on self-assembly approach is the simplest, cost effective technique. Selfassembly is one of the most important "molecular engineering" strategies used in fabricating complex functional structures, from micro to the molecular levels, utilising the advantage of self-interaction of molecules. Molecular self-assembly is a strategy for nanofabrication that involves designer molecules and supramolecular entities so that molecules naturally aggregate into specific desired structures $[1,2]$. This method reduces many difficult steps in nanofabrication, those involving atomic-level modifications of the structures. Moreover, molecular self-assembly tends to produce structures that are relatively defect-free and self-healing, because the target structures are selective with thermodynamically stable assembly between the possible configurations. Several self-assembly methods have been developed in the recent past, such as phase-separation of copolymers, formation of pores in alumina, liquid crystals, zerogels, and polymer spheres templating [3-5]. At molecular levels, one of the examples of self-assembly is the intercalation strategy wherein the organic entities are spacefilled within naturally self-assembled crystalline inorganic semiconductor hosts, with an opportunity to produce a very special and tailor-made semiconductor, known as inorganicorganic hybrids [6-8]. In a macro level, mono dispersed mesa sized spherical colloids are self-assembled to form three-dimensionaly periodic lattices and are famously known as synthetic opals (3D photonic crystals) [9-17]. Another relatively easy and cost-effective methodology to produce nano to wavelength-scaled photonic structures with longrange order is through self-organized systems, which can be used to create periodic patterns, followed by material filling into the interstitial spaces through techniques like electrochemical deposition. This approach is called templated self-assembly. Overall, for large-scale production, the selfassembly and template assisted self-assembly techniques are better alternatives to top-down technology. 


\section{Naturally Self-Assembled Nanosystems}

Though inorganic semiconductors are still a material of choice for high-performance semiconductor devices, in recent years organic semiconductors have attracted considerable interest for applications as active materials in lowcost semiconductor devices. For example, displays based on organic light-emitting diodes have already made their way into commercial products, and semiconductor devices like organic FETs have been demonstrated and are being rapidly improved [18-22]. Analogous to low-dimensional inorganic semiconductors are low-dimensional organic nanolayers, which are basically a self-assembly of organic molecules (e.g., J-aggregates) [23-25]. Significant advantages of these self-organized molecular nanostructures ( $J$-aggregates) are the ultra-sharp absorption line widths with giant oscillator strengths, especially room-temperature performance. $J$ aggregates exhibit a very narrow and red-shifted electronic absorption band ( $J$ band) and strong fluorescence with a small Stokes shift. These characteristic optical properties, which are the origins of their expected functions, are explained by the interaction between the transition dipole moments [26, 27]. However, while organic semiconductors have obvious advantages, due to simple fabrication and high performance, the main draw-backs are a slow-optical response, lack of thermal/mechanical durability, and most importantly limited life span.

\section{Naturally Self-Assembled Inorganic-Organic (IO) Hybrid Systems and Applications}

Inorganic-organic (IO) hybrid nanostructures have recently emerged as highly-promising systems for applications as optoelectronic devices, opening up a new dimension to nanotechnology, as unique replacement to their inorganic and organic counterparts. These hybrid systems have great advantage to combine distinct properties of inorganic and organic components within a single-molecular material. The art of combining dissimilar components to yield improved materials is not actually new: ancient building construction material, adobe [28], was made from a mixture of clay (inorganic) and straw (organic). Another classical example is "blue Maya color" developed in around 900 A.D., is an IO-hybrid composite. In fact the Maya blue is an inorganicorganic hybrid composed of palygorskite clay and organic indigo dye $\mathrm{C}_{16} \mathrm{H}_{10} \mathrm{~N}_{2} \mathrm{O}_{2}[29,30]$. The most characteristic beauty is its unusual stability; even after centuries of exposure to heat, humidity, and extreme atmospheric conditions, the color hardly faded.

Among various IO-hybrids, one of the most interesting and well-studied materials is a perovskite type hybrid [31]. These self-organized materials are derived from the general structure form of $\mathrm{AMX}_{3}$ where $\mathrm{A}$ is an organic moiety, $\mathrm{M}$ is a divalent metal (such as $\mathrm{Pb}^{2+}, \mathrm{Sn}^{2+}, \mathrm{Ge}^{2+}, \mathrm{Cu}^{2+}$, $\mathrm{Ni}^{2+}, \mathrm{Mn}^{2+}, \mathrm{Fe}^{2+}, \mathrm{Co}^{2+}$, and $\left.\mathrm{Eu}^{2+}\right)$, and $\mathrm{X}$ is a halide (such as $\mathrm{I}, \mathrm{Br}$, and $\mathrm{Cl}$ ). This simple $3 \mathrm{D}$ structure $\mathrm{AMX}_{3}$ consists of corner-sharing $\mathrm{MX}_{6}$ octahedra extended in three dimensions, where the " $\mathrm{A}$ " cations are located in the larger
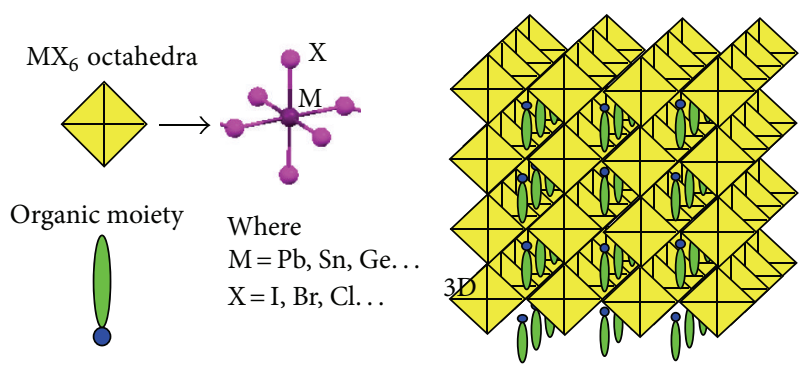

FIGURE 1: Schematic of $\mathrm{MX}_{6}$ octahedra and the organic moiety of the basic $\mathrm{AMX}_{3}$ perovskite unit cell and three-dimensional network formed by $\mathrm{AMX}_{3}$ perovskite unit cells.

12-fold coordinated voids between the octahedra (Figure 1). These self-assembling inorganic-organic perovskites adopt an alternating framework of semiconducting inorganic sheets and organic layers. The increasing interest is because of the ability to derive low-dimensional crystals, which show unique crystal structure and physical and optical properties, from parent $3 \mathrm{D}$ networks of $\mathrm{AMX}_{3}$ from simple and effective natural self-assembly [32-43]. These materials involve different types of interactions allowing the assembly of complex and highly-ordered structures with various bonding schemes. The chemical bonding involved in these IO-hybrid assembled systems are generally described as

(i) covalent/ionic bonding within the inorganic network which favors the formation of sheets of cornersharing metal halide octahedra,

(ii) hydrogen/ionic bonding between the organic cations and the halogens in the inorganic sheets,

(iii) various weak interactions like Van der Waals interactions between the organic R-groups.

Many structural, electrical, thermochromic, and magnetic studies were carried out from almost a decade, to explore the advantages of IO-hybrids over organic and inorganic counterparts [44-46], These hybrids have an advantage of structural flexibility to choose suitable organic spacers (usually monofunctional or difunctional amines). The crystallographic orientation and the thickness of the perovskite sheets can be tailored as per the choice of appropriate organic cations. In other words, inorganic units can be selforganized into low-dimensional crystals of zero-(0D), one(1D) and two-(2D) dimensional networks (Figure 2). In 0D networks, $\mathrm{MX}_{6}$ octahedra are isolated and are surrounded with the organic spacers. In $1 \mathrm{D}$ networks, metal halides $\left(\mathrm{MX}_{6}\right.$ octahedra) are extended as a chain along one direction with corner/edge/face shared to form 1D hybrid. Similarly, inorganic network can be extended as layered sheets with corner shared $\mathrm{MX}_{6}$ octahedra to form $2 \mathrm{D}$ networks. In $2 \mathrm{D}$, inorganic and organic layers are stacked alternatively with orientation along a specific crystal direction.

During synthesis, the organic moieties, apart from controlling the dimensionality, can also alter the crystallographic orientation of the parent network. For example, based on the organic moiety interaction with metal halide network, 


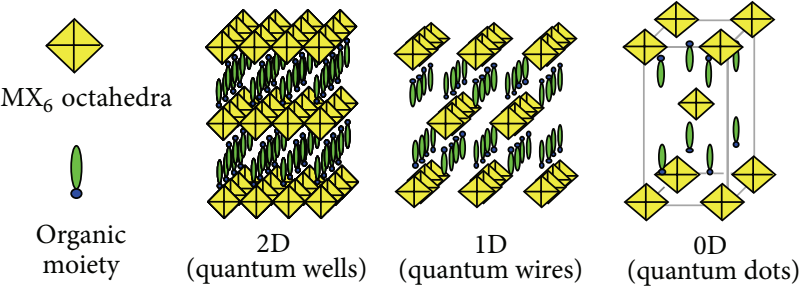

Figure 2: Schematic of 2D, 1D, and 0D IO-hybrid derived from parent $\mathrm{AMX}_{3}$ type 3D IO-hybrid.

the resultant network can deviate from $\langle 100\rangle$ oriented $2 \mathrm{D}$ network [47] to $1 \mathrm{D}$ dimensional $\langle 110\rangle$ oriented hybrid structures also [48, 49]. Under special circumstances, based on organic moiety conformation, the metal halides may selfassemble into either edge sharing or face sharing of metal halide octahedra, forming various low dimensional inorganic halide networks of different orientations. Based on such different networks, these hybrids show marked variation in their structural and optical features [50-59].

Several studies were carried out in the recent past to prove the potential ability of IO-hybrids in photonic applications: electro-absorption and electroluminescence [60-64], photoconductive devices, $[65,66]$, optical nonlinear devices $[67$, 68], stark effect [69] magneto- absorption, and spontaneous magnetization [70, 71]. Apart from linear optical studies, high-optical excitation effects such as ultrafast dynamics of excitons [50,72], observation of higher-order excitons (biexciton and triexciton) [51, 52, 73-75], and even an attempt of biexciton lasing [76] were also reported. Photonic devices such as thin film transistors (TFTs), inorganic-organic fieldeffect transistors (IOFETs), inorganic-organic light emitting diodes (IOLEDs), and scintillators were also been successfully demonstrated [77-79].

\section{Naturally Self-Assembled Two-Dimensional IO-Hybrid Systems}

Among the several low-dimensional hybrids mentioned before, 2D hybrids are of special interest. The 2D $(\langle 100\rangle$ oriented) hybrids are analogous to natural multiple quantum wells (MQWs), where inorganic and organic sheets (of molecular level sizes) are alternatively stacked. This is of special attraction because such natural MQWs are easily achieved from solution-processing techniques, without any involvement of laborious instrumentation like molecular beam epitaxy deposition. Various possible layered schemes of these MQWs are shown in Figure 3. Depending on respective inorganic and organic bandgaps, these MQWs can be classified [80] into Type I, II, or III (Figure 3).

In Type I, the conduction band of the inorganic layer is generally below that of the organic layer, and the valence band is above that of the organic layer (Figure 3). Therefore, inorganic sheets act as "quantum wells" for both electrons and holes leading to Type I heterostructure. Similarly, if larger bandgap inorganic sheets are integrated with more complex, conjugated organic cations (with bandgap less than

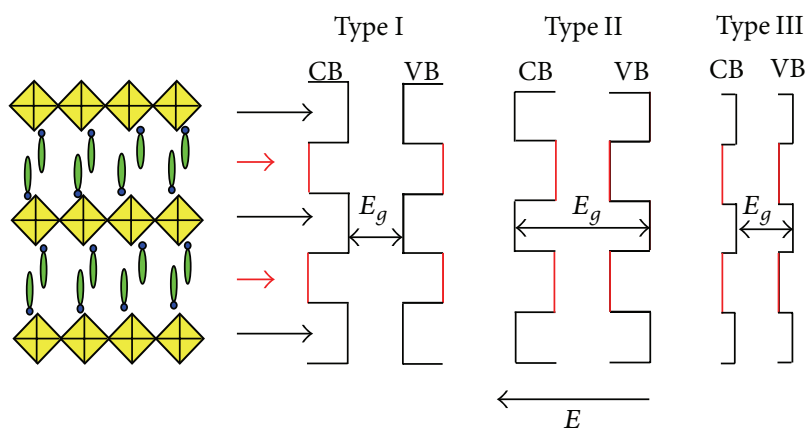

FIGURE 3: 2D IO-hybrid structure and several possible energy level schemes.

inorganic layer), the well and barrier layer roles can be reversed [77] forming Type II heterostructure (Figure 3). In special cases, by appropriate modifications of the chemistry of the organic and inorganic layers, the bandgaps for the organic and inorganic layers can also be offset, leading to Type III heterostructure, in which the wells for the electrons and holes are in different layers. The present study deals with the IO-hybrid system of $\mathrm{R}-\mathrm{PbI}_{4}$ (where $\mathrm{R}$ is organic), having Type I structure, where the inorganic (PbI network $\sim 3 \mathrm{eV}$ ) bandgap is much less than the organic bandgap (4 to $6 \mathrm{eV})$, therefore, the electron-hole confinement is solely within inorganic network.

The most influencing factors in 2D IO-hybrids are (1) the choice of organic moiety, (2) how the organic moiety intercalates into the inorganic network (vice versa), thereby altering the structural rearrangement and the consequent energy band structure, (3) quantum confinement due to quantumlimit widths of the individual organic and inorganics, and (4) the dielectric contrast between the organic and inorganic sheets. Technically the last two are dependent on first two factors.

\section{Structure and Fabrication Strategies of Naturally Self-Assembled IO-Hybrid Systems}

5.1. Structure of Naturally Self-Assembled IO-Hybrids. Generic way of visualization of these IO-hybrids is intercalation of organic guest moieties into a parent crystalline host. Recent efforts in the crystal engineering resulted into the reduction of structures into $0,1,2$, or 3 - low-dimensional hybrid networks [32, 33, 77, 83-87]. The dimensionality of these IO-hybrids, based on the bridging of organic moiety between the MX one-dimensional planes, is critically dependent on (1) the choice of hydrogen bonding scheme between protonated amine terminal group(s) of organic moiety and the MX network and (2) the driving force, size, and shape of the organic molecule [80]. The simplest $\mathrm{MX}_{4}{ }^{2-}$ network consists of corner-sharing metal halide octahedra oriented along $\langle 100\rangle$ plane and, based on how the organic is 


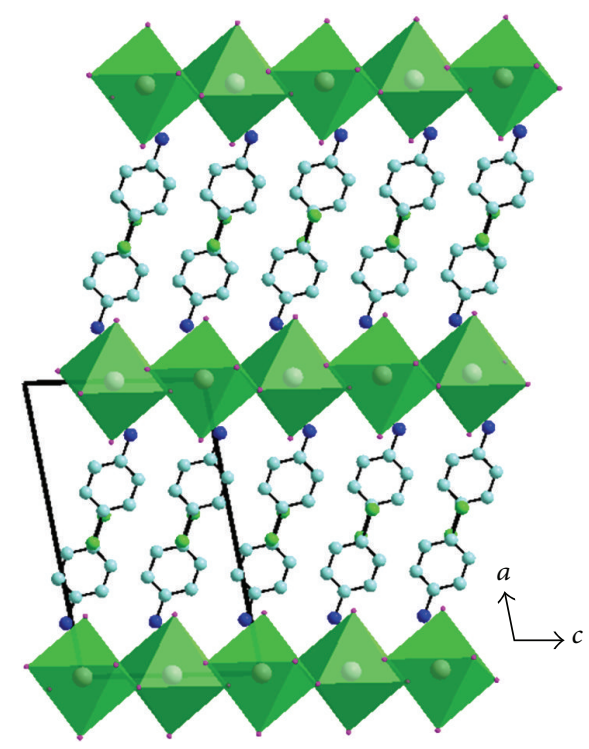

(a)

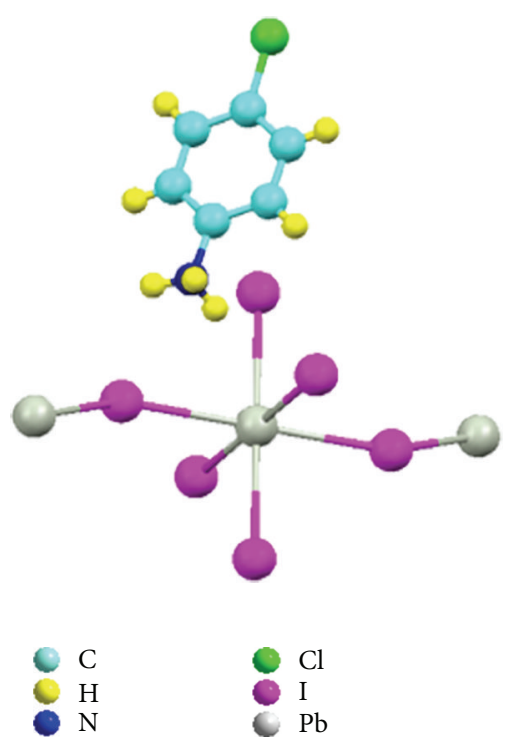

(b)

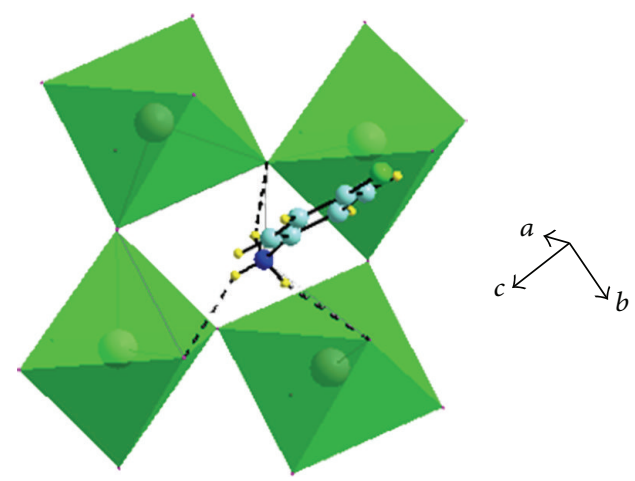

(c)

FIgURE 4: (a) Packing structure, (b) asymmetric unit, and (c) NH-I terminal halide configuration (equilateral triangle configuration) of CAPI [81].

intercalated into the parental network, intercalated structures of $0 \mathrm{D}, 1 \mathrm{D}, 2 \mathrm{D}$, and $3 \mathrm{D}$ can be expected [32, 33, 48, 86, 88, 89].

In the two-dimensional $\mathrm{R}-\mathrm{MX}_{4}$ type hybrids, $\left(\mathrm{MX}_{4}\right)^{2-}$ octahedral network sheets are stacked up along $\langle 100\rangle$ direction with alternate layers of organic moieties. The crystallographic information for one of the IO-hybrid (4$\left.\mathrm{ClC}_{6} \mathrm{H}_{4} \mathrm{NH}_{3}\right)_{2} \mathrm{PbI}_{4}(\mathrm{CAPI})$ has been presented in Figure 4. CAPI IO-hybrid crystallizes in the monoclinic space group $\mathrm{P} 2{ }_{1} / \mathrm{c}$ in which the asymmetric unit consists of half a $\left(\mathrm{PbI}_{4}\right)^{2-}$ anion and one $\left(\mathrm{Cl}-\mathrm{C}_{6} \mathrm{H}_{4} \mathrm{NH}_{3}\right)^{+}$cation. These structures comprises of well-ordered organic and inorganic layers, arranged alternately stacked along the $a$-direction with layers infinitely extended in the $b c$ plane.

5.2. General View of Synthesis, Fabrication, and Implications. Many device applications demand simple and effective fabrication protocols specially the techniques to make highly uniform device-quality thin films. IO-hybrids are generally fabricated from conventional solution processing methods, and single crystals are harvested by slow evaporation technique [90-94]. Though several synthesis recipes are available, a simpler, generalized, high product yield, and commercially viable process is as follows. Stoichiometric quantities of organic moiety and inorganic $\left(\mathrm{PbI}_{2}\right)$ were mixed with concentrated aqueous $\mathrm{HI}$ at $60^{\circ} \mathrm{C}$. The resultant solution was allowed to rest at $60^{\circ} \mathrm{C}$ for an hour and then cooled slowly to room temperature without stirring. The precipitate, thus, obtained was filtered off and dried.

The general synthesis is as follows:

$$
2\left(\mathrm{R}-\mathrm{NH}_{2}\right)+\mathrm{PbI}_{2}+\mathrm{HI} \longrightarrow\left(\mathrm{R}-\mathrm{NH}_{3}\right) \mathrm{PbI}_{4} \text {. }
$$

Single crystals of the respective compounds were harvested from slow evaporation process by dissolving the compound in a sparingly soluble solvent. However, the synthesis procedure slightly varies from its generic route depending on the nature of organic moiety.

From the application perspective, thin film processing demands to achieve easy and controlled thickness/ morphology over large areas and most importantly highly oriented IO-hybrids. The applications of IO-hybrids will be 
immense only if the fabrication parameters are precisely controlled. For the same reason, one has to develop methods of fabrication that can be carefully predicted and controlled for a predetermined technological application. Usual way of fabricating these thin films is from spin-coating of IO-hybrid solutions onto a desired substrate. Although other techniques like single- and double-source thermal vapor deposition, Langmuir Blodgett (LB) method, layer by layer deposition, spray pyrolysis, and low-temperature melting process had been employed to obtain films, it is always difficult to find empirical conditions and processes to obtain well-ordered thin films of these IO-hybrids [95-100]. Especially the applicability of thermal vapor deposition technique is limited due to stability and contamination issues and to balance organic and inorganic evaporation rates simultaneously. Recently, Rikukawa group [95] had developed layer-by-layer selfassembly method to fabricate ultra-thin films of bifunctional amino end-group based IO-hybrid. This method is based on alternate dipping of hydrophilic substrates in organic iodide and lead halides solutions followed by repeated washing to remove unreacted residuals, and this procedure was repeated several times to obtain required self-assembly films, up to 12 layers.

We have recently explored one of the much simpler, but efficient technique, so-called intercalation process to fabricate highly-ordered IO-hybrids over centimeter size lateral dimensions. In fact, the word intercalation in general refers to insertion of guest into self- assembled 2D/3D solids. Gieseking [101] and MacEwan [102] showed, for the first time, the ability of the formation of IO-hybrid by intercalation of organic cations into layered and charged inorganic hosts and further extended to neutral guest/hosts by Bradley [103]. Owing to the intense interest in new nanocomposite functional hybrid materials for fundamental and device-oriented research, new intercalation chemistry has been established [104]. For 2D layered hybrids it is essential to focus on both new hybrids as well as highly ordered films, however, the later one has not been widely considered.

As mentioned before, the kinetics and layer formation during intercalation are critically dependent on the nature and shape of the guest moiety, concentration of guest molecules, thickness of parent films, intercalation time, and the solvent used [7]. The schematic of intercalation strategy of IO-hybrid for a high-quality thin film fabrication is demonstrated in Figure 5. When predeposited layered $\mathrm{PbI}_{2}$ film is intercalated with presynthesized organic iodide, the structural network of $\mathrm{PbI}_{2}$ and the conformation of organic chain are changed to form IO-hybrids. Uniform 2D IO-hybrids films can, thus, be fabricated by an appropriate choice of organic moieties. A brief description of the intercalation process is explained here by taking an example of the IO-hybrid 2(1-cyclohexenyl) ethylammonium tetraiodoplumbate $\left(\left(\mathrm{C}_{6} \mathrm{H}_{9} \mathrm{C}_{2} \mathrm{H}_{4} \mathrm{NH}_{3}\right)_{2} \mathrm{PbI}_{4}\right.$, CHPI) [7]. Theorganic iodide, 2-(1-cyclohexenyl) ethylammonium iodide $\left(\mathrm{C}_{6} \mathrm{H}_{9} \mathrm{C}_{2} \mathrm{H}_{4} \mathrm{NH}_{3} \mathrm{I}\right)$ (CHI) is formed when $1 \mathrm{~mL}$ of 2-(1cyclohexenyl) ethylamine was added to $2.1 \mathrm{~mL}$ of $\mathrm{HI}(47 \%)$. The obtained light yellow precipitate $\mathrm{CHI}$ eventually has been filtered and dried for further use. Similar is the method for other organic iodide synthesis. Suitable solvent (such as

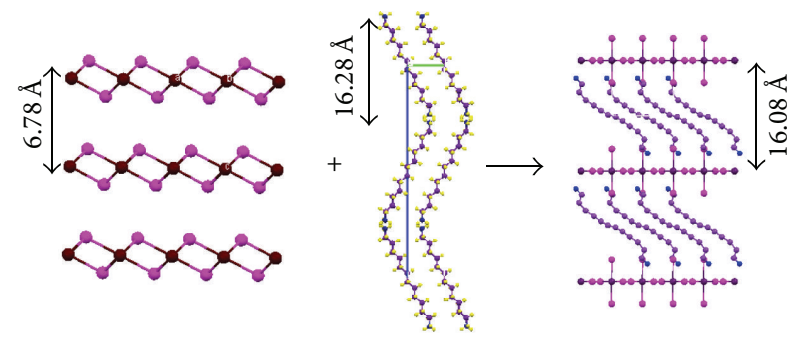

FIGURE 5: Schematic representation of intercalation process for 2D layered IO-hybrid thin films [7]. Essentially the intercalation method involves the intercalation of organic moiety into intestinal spaces of layered inorganic host to obtain desired inorganic-organic exfoliated layered hybrid.

toluene or a combination of toluene and isopropanol) is taken to dissolve organic iodide. Special care has to be taken on the solvent ratio so as to dissolve only the organic iodide but not $\mathrm{PbI}_{2}$ or the resultant hybrid. Finally, the deposited $\mathrm{PbI}_{2}$ thin films are dipped into organic iodide films, with a controlled speed and for specific time, to obtain desired IO-hybrid films. The resultant films, fabricated by the intercalation process, were smooth and uniform over a large area and had shown relatively well-stacked (00l oriented) inorganic and organic monolayers [7] (Figure 6).

\section{Room-Temperature Optical Exciton Features}

Exciton absorption/emission features in these low-dimensional IO-hybrids, especially in 2D hybrids, are significantly enhanced as compared to the 3D counterpart, due to the lowdimensionality. In the $\mathrm{PbI}$ based 2D IO-hybrids, electrons are excited from the valence band (VB), consisting of a mixture of $\mathrm{Pb}(6 \mathrm{~s})$ and I (5p) states, to the conduction band (CB), derived mainly from the $\mathrm{Pb}(6 \mathrm{p})$ states, leaving holes in the VB. An electron and hole pair up to form an exciton via coulomb interaction, and the resulted excitons produce photoluminescence by radiative recombination $[105,106]$. The enhancement of exciton features in $2 \mathrm{D}$ systems is a well-known phenomenon because of the spatial electron and hole confinement in a very thin and deep quantum wells and, hence, multiples the exciton binding energy, enabling quantum confinement effect. Apart from the usual quantum confinement in these natural $M Q W s$, the excitons binding energies are further enhanced due to large contrast in dielectric constants of organic and inorganic layers. Such large binding energy enhancement, leading to strong roomtemperature exciton features, often is referred as dielectric confinement effects [107, 108]. Ishihara et al. [105] in 1989, reported for the first time the exciton binding energy of $\left(\mathrm{C}_{10} \mathrm{H}_{21} \mathrm{NH}_{3}\right)_{2} \mathrm{PbI}_{4}(\mathrm{Cl} 10 \mathrm{PI})$, which is $370 \mathrm{meV}$ and is much higher than that of bulk $\mathrm{PbI}_{2},(\sim 30 \mathrm{meV})[106]$. This was wellaccounted from dielectric confinement assumption, where the dielectric difference between "well" and "barrier" induces strong columbic interaction between an electron and a hole 


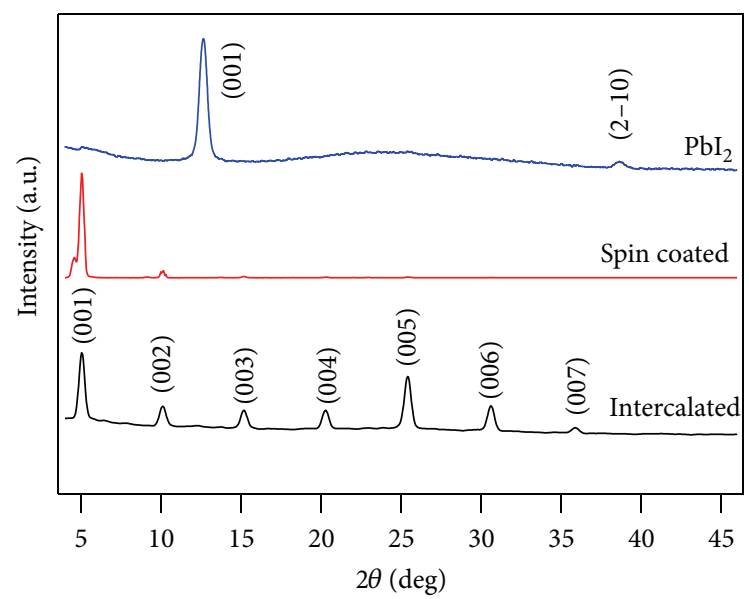

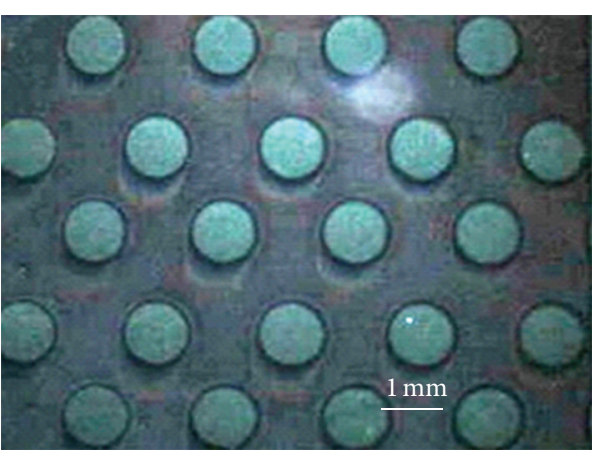

(a)

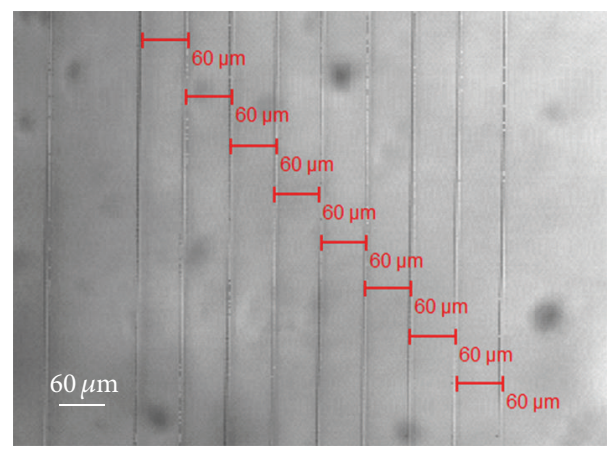

(b)

FIgURE 6: X-ray diffraction patterns of pure $\mathrm{PbI}_{2}$ film, spin-coated CHPI (from synthesized CHPI), and intercalated CHPI films (for 10 seconds) [7]. Bottom microscopic reflection images represent the obtained periodic photonic structures using top-down technology: (a) patterned structures from direct deposition of materials from templates using intercalation technique and (b) femtosecond laser written structures on CHPI thin films.

and as a consequence the binding energy of the exciton is 12 times larger than that of $\mathrm{PbI}_{2}[84,105,107-109]$.

For example, in CAPI (Figure 4), the inorganic and organic layer thicknesses are estimated to be $6 \AA$ and $10 \AA$. This layered structure resembles $M Q W s$, where inorganic layer has a bandgap of $\sim 3 \mathrm{eV}$ forming "well," and organic layer has a bandgap $\sim 6 \mathrm{eV}$ forming "barrier." Figure 7 shows the typical photoluminescence (PL) and absorption spectra of CAPI thin film.

The room-temperature absorption of CAPI shows two principal absorptions: a broad absorption at $\sim 400 \mathrm{~nm}$ and a strong narrow peak at $\sim 480 \mathrm{~nm}$ (Figure 7 (black)). While the former is attributed to the charge-transfer transition between the organic and inorganic layers, the narrow absorption peak at about $480 \mathrm{~nm}$ is attributed to the lowest exciton within the inorganic layers $[84,105,110]$. CAPI thin films show strong room-temperature photoluminescence (PL) at $\sim 485 \mathrm{~nm}$ upon UV excitation (Figure 7 (red)). The PL spectrum of CAPI has narrow line shape with spectral width $\sim 15 \mathrm{~nm}$. The oscillator strength of exciton absorption peak obtained for the hybrid CAPI thin film (of thickness $100 \mathrm{~nm}$ )

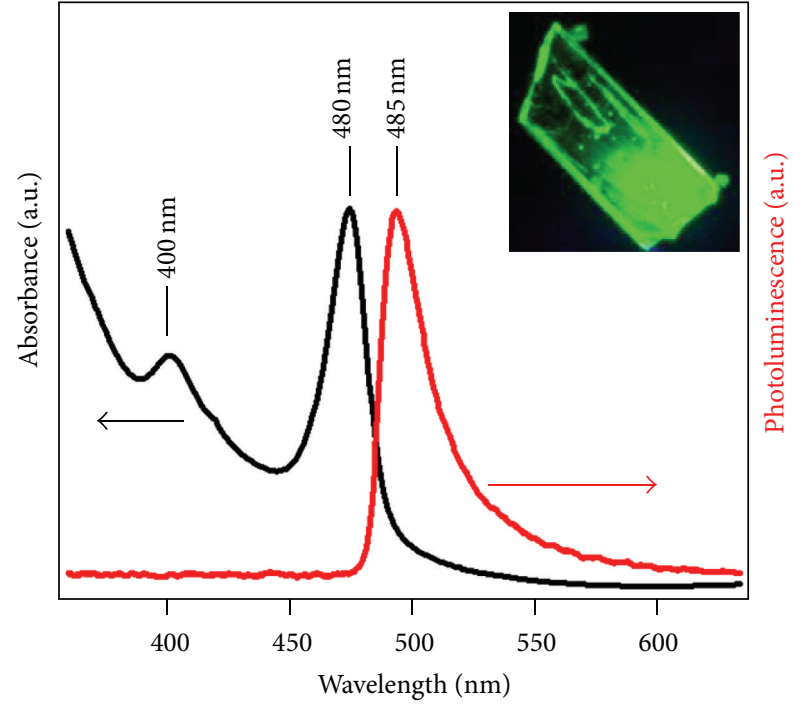

FIgURE 7: Absorption and PL spectra of the 2D layered IOhybrid, CAPI, thin film [81]. Inset shows typical single crystal PL microscope image. 


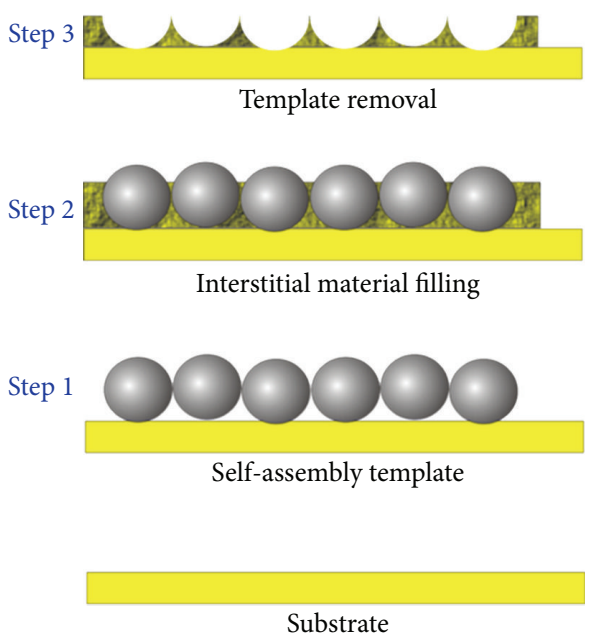

(a)

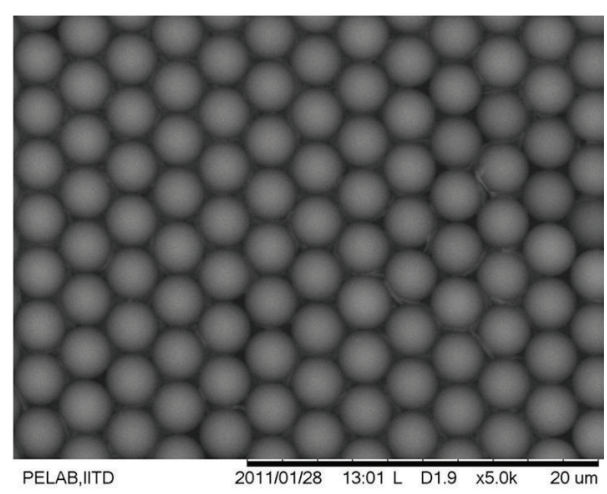

(b)

FIGURE 8: (a) Schematic representation of self-assembly template assisted fabrication of photonic structures and (b) polymer microsphere templates.

is $f=6.5 \times 10^{15} \mathrm{~cm}^{-2}$. Since, for the film thickness of $100 \mathrm{~nm}$, there are $\sim 70$ quantum wells, the oscillator strength per quantum-well $f_{\mathrm{qw}}=9.2 \times 10^{13} \mathrm{~cm}^{-2}$. This value is an order of magnitude higher than the conventional inorganic quantum wells such as InGaAs structure [111].

Despite some understanding on the dependence of exciton energies of 2D layered IO-hybrids on various parameters like the inorganic well width and organic barrier separation, the dielectric contrast and the inorganic layer geometrical arrangement, quantitative calculations of exciton binding energies remain out of reach. A systematic correlation between the exciton energies and a specific structural feature has recently been established and discussed [110, 112]. However, the structural features are strongly dependent on several factors such as (1) disorder or conformation of the organic moiety, (2) crystal packing, (3) arrangement of inorganic layers, and (4) position of tagging of ammonium group in organic moiety to the $\mathrm{PbI}$ network. As a consequence the optical excitons features are also strongly dependent on the studied IO-hybrid thin films based on organic moiety conformation, solvent used, temperature, and the film thickness [110, 113-115]. Special control over thickness of the IO-hybrid film is critical for device oriented $3 \mathrm{D}$ structure fabrication, to avoid the exciton deformation and defect related emission/absorption features.

\section{Templated Self-Assembled Microstructures}

Carving useful materials itself into the nano to micron-sized structures using simple bottom-up technology is economically viable. This new approach is based on the natural self-assembly of templates and subsequently space filling the voids either by precipitation via chemical routes or by the electrochemical reduction of materials (Figure 8). Therefore, nano-/microstructuring using templates such as artificial polymer opals and liquid crystal is a whole new class of research. These micro-/nanostructures have potential applications such as tunable plasmonic bandgaps [116], novel types of liquid crystal displays [117], and nanolaser cavities [118]. These macroporous materials are already available in the market as surface enhanced Raman scattering (SERS) devices [119]. Despite the fact that the methodology offers highly ordered structures with very large single-crystalline domains, it has so far been restricted only to metals.

However, fabrication of self-assembled semiconductor photonic structures is still scarce, particularly understanding the chemistry for interstitial filling and deposition for semiconductors and adequate interconnectivity between the pores [120-123]. Electrochemical deposition is one of the low-cost deposition techniques which is an optimal bottom up technique for complete interstitial space filling of desired material through various types of templates. Over the years, conducting thin films ( $\mathrm{Ag}, \mathrm{Au}$, etc.) were deposited on various semiconducting and conducting substrates utilizing this technique, but the deposition of semiconductors, organic materials, and polymers have always been a formidable task, due to low-conductivity issues. Constant research work on electrodeposition finally emerged out to be more useful than expected when deposition of semiconductors and several organic materials had been possible. However, structural and optoelectronic properties of semiconductors are critically affected by the preparation conditions such as fabrication method, types of substrates, thickness, and annealing conditions. Nevertheless, it is necessary to optimize the fabrication conditions and postprocessing methods for desired applications.

Here the template assisted method to fabricate periodic structures from $50 \mathrm{~nm}$ to as big as 20 micron is exemplified. After having optimized electrodeposition conditions, such as electrolyte recipe, surface quality, structural, and optical properties, we have extensively investigated to fabricate $2 \mathrm{D}$ and $3 \mathrm{D}$ periodic and quasiperiodic nano/micro-structure 

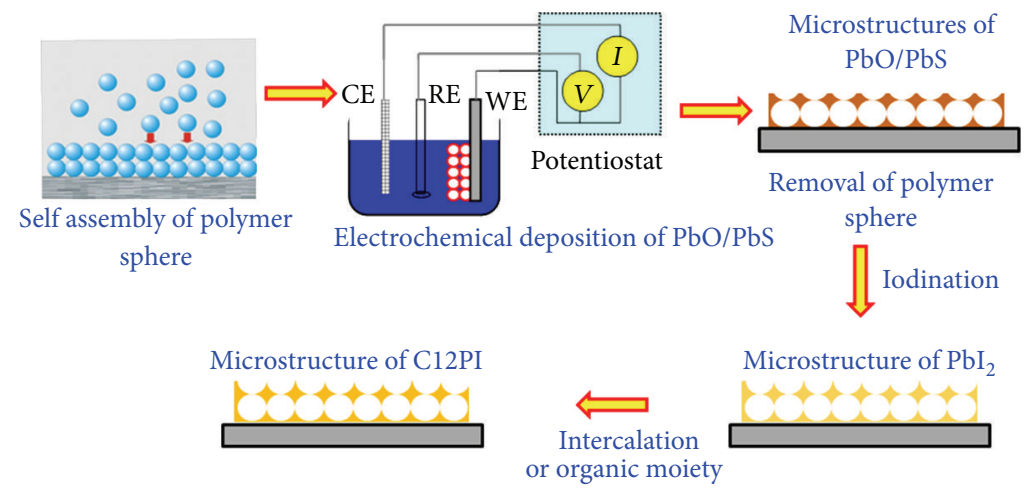

FIGURE 9: Schematic representation of carving naturally self-assembled hybrid systems into 2D/3D microstructures from template selfassembly method.

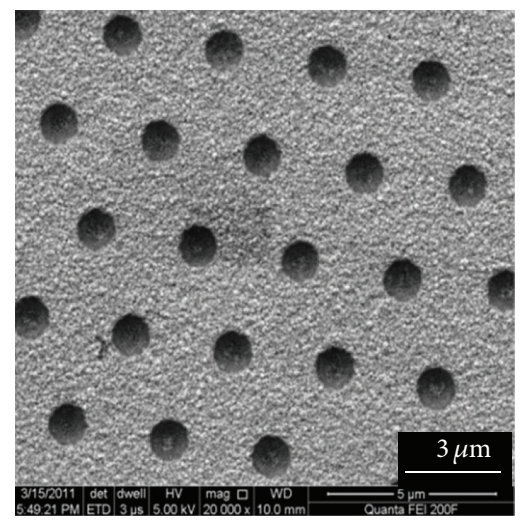

$\mathrm{PbO}$

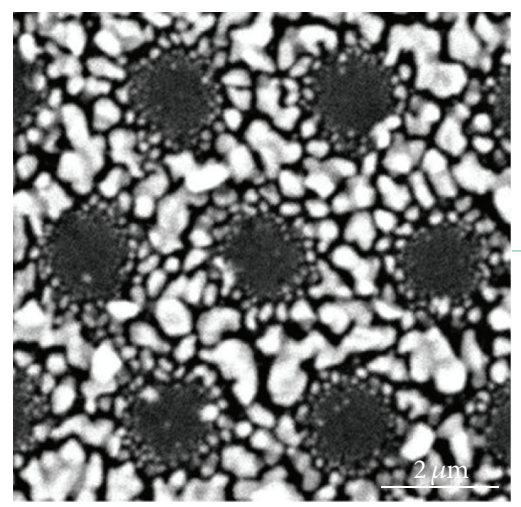

$\mathrm{PbS}$

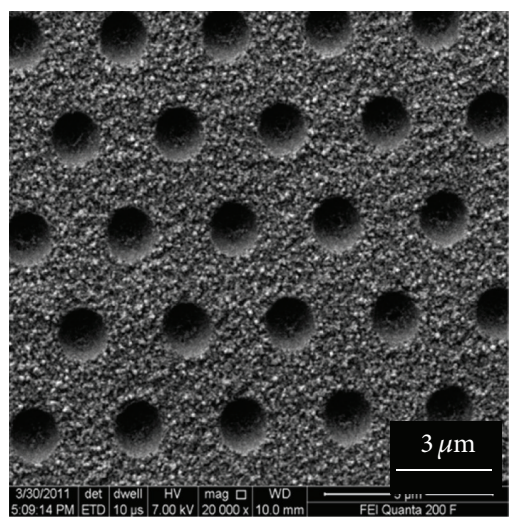

$\mathrm{PbI}_{2}$

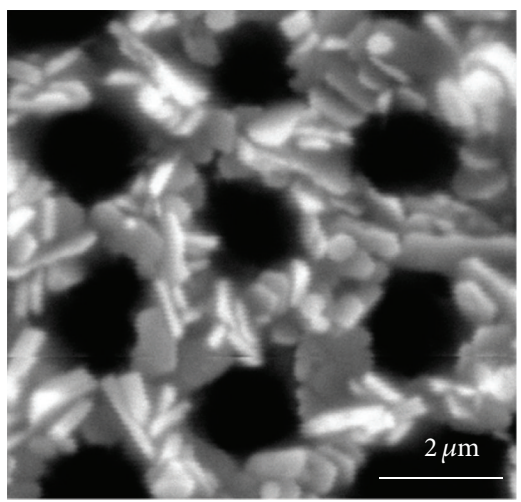

$\mathrm{PbI}_{2}$

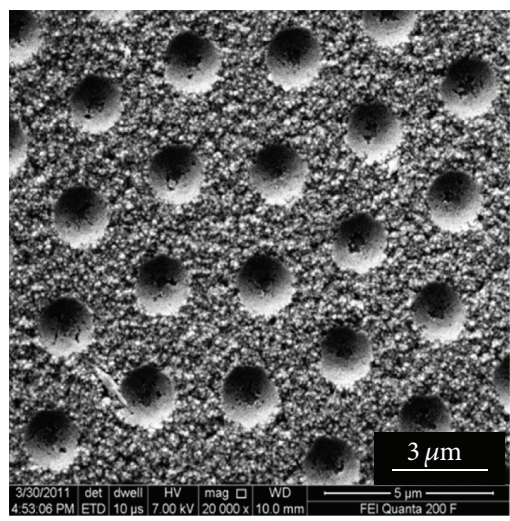

C12PI

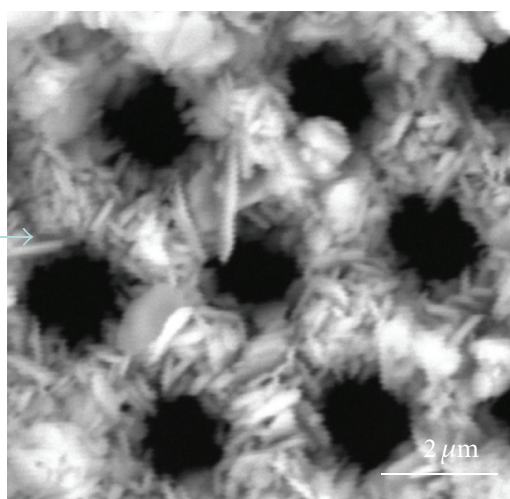

C12PI

FIGURE 10: Scanning electron microscope images of template-assisted $\mathrm{PbO}, \mathrm{PbI}_{2}, \mathrm{PbS}$, and C12PI microstructures [82].

from template-assisted growth techniques [11, 12, 17, 82]. During this investigation, several composite semiconductors such as $\mathrm{CdSe}, \mathrm{CdTe}, \mathrm{ZnO}, \mathrm{PbO}, \mathrm{PbS}$, and $\mathrm{PbI}_{2}$ are successfully fabricated and their optoelectronic properties are thoroughly investigated. We further demonstrated micronscale $2 \mathrm{D}$ periodic highly emitting IO-hybrid structures, using template-assisted electrochemical growth followed by threestep processing, which can be easily extended to wave-length scale and nanoscale structures.
The systematic procedure has been explained in the schematic diagram (Figure 9). Essentially the electrodeposited $\mathrm{PbO} / \mathrm{PbS}$ microstructures (Figure 10) are iodinised to obtain $\mathrm{PbI}_{2}$ microstructures, then the presynthesized organic iodide is intercalated into $\mathrm{PbI}_{2}$ to obtain desired IO-hybrid microstructures. During the process, the thickness of IOhybrid film has to be fixed and such thickness optimization is required because these type of IO-hybrids are sensitive to thickness induced stacking imperfections, which directly 


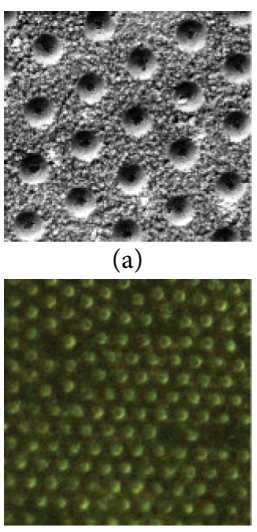

(b)

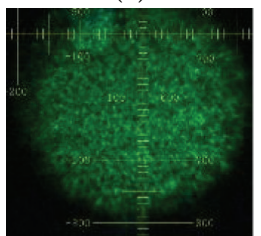

(c)

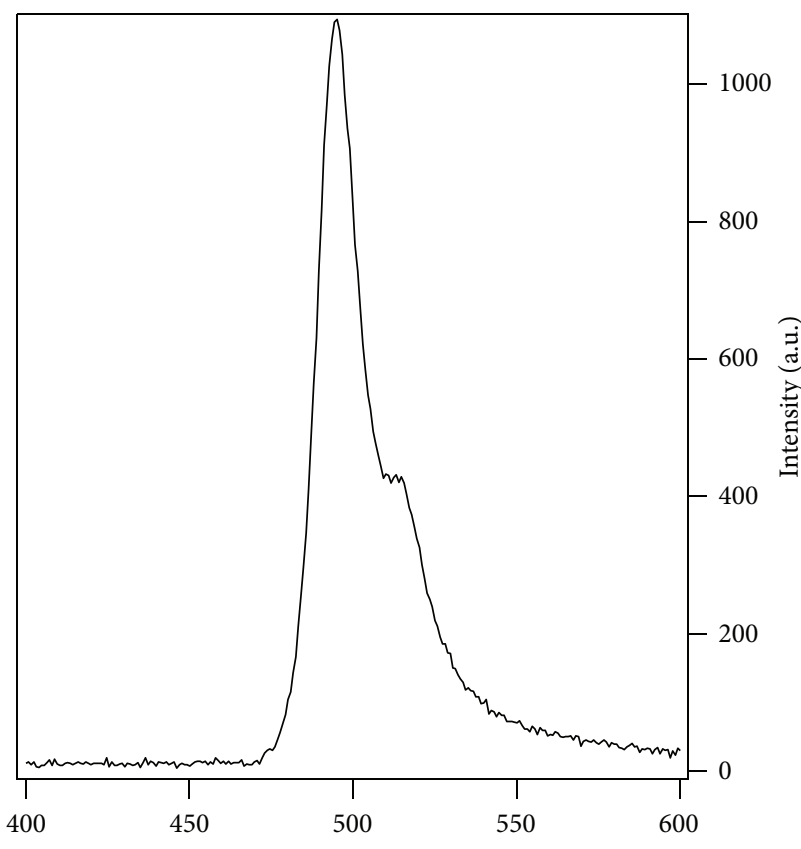

Wavelength (nm)

(d)

Figure 11: (a) SEM, (b) dark field microscope, and (c) PL microscope images $\left(\lambda_{\text {ex }} \sim 410 \mathrm{~nm}\right)$, (d) corresponding to the PL spectra from the fabricated C12PI microstructures [82].

results into rapid change in their exciton-related emission/absorption behavior. The thickness-dependent disorder produce uneven crystalline planes, and as a consequence, the shift in the exciton PL peak and/or broad defect emission were observed [81, 113].

The fabricated IO-hybrid microstructures (Figures 10 and 11) are uniform over large areas and are highly luminescent. In general, the fabrication of $3 \mathrm{D}$ structures from infiltration methods, using conventionally synthesized hybrids is difficult due to surface morphology issues [81]. In contrast to that, the hybrid structures fabricated from this novel method pave the way for new directions in the fabrication of different photonic structures of IO-hybrids. As a hybrid nanosystem, low-dimensional IO-hybrid systems have shown potential applications and those applications were reviewed in previous sections. Photonic structures of these nano systems could further improve the optical properties and hence would find device applications in the area of optoelectronics.

\section{Conclusions}

Fabrication, structural and optical exciton features of naturally self-assembled low-dimensional IO-hybrid nano systems were discussed. While the fabrication of these selfassembled systems are usually from solution chemistry techniques, a novel device-compatible thin film fabrication from very inexpensive method, that is, intercalation, was reviewed. Finally, the designing and fabrication of optoelectroniccompatible photonic architectures from these IO-hybrids, especially from template-assisted method, have been clearly discussed.

\section{Acknowledgments}

This work is funded from High-impact Research initiative of IIT Delhi, UK-India Education Research Initiative (UKIERI), Nano Research Facility (MCIT, Govt. India funded) of IIT Delhi, and the Department of Science and Technology (DST, Govt. of India). Authors are thankful to Professor Jeremy Baumberg, University of Cambridge, UK, for his valuable support and fruitful discussions.

\section{References}

[1] G. M. Whitesides and M. Boncheva, "Beyond molecules: selfassembly of mesoscopic and macroscopic components," Proceedings of the National Academy of Sciences of the United States of America, vol. 99, no. 8, pp. 4769-4774, 2002.

[2] J. M. Lehn, "Toward self-organization and complex matter," Science, vol. 295, no. 5564, pp. 2400-2403, 2002.

[3] P. Yang, D. Zhao, D. I. Margolese, B. F. Chmelka, and G. D. Stucky, "Block copolymer templating syntheses of mesoporous metal oxides with large ordering lengths and semicrystalline framework," Chemistry of Materials, vol. 11, no. 10, pp. 28132826, 1999.

[4] S. Mahima, R. Kannan, I. Komath, M. Aslam, and V. K. Pillai, "Synthesis of platinum Y-junction nanostructures using hierarchically designed alumina templates and their enhanced electrocatalytic activity for fuel-cell applications," Chemistry of Materials, vol. 20, no. 3, pp. 601-603, 2008.

[5] G. S. Attard, C. G. Göltner, J. M. Corker, S. Henke, and R. H. Templer, "Liquid-crystal templates for nanostructured metals," Angewandte Chemie (International Edition in English), vol. 36, no. 12 , pp. 1315-1317, 1997. 
[6] K. J. Bachmann and J. L. Shay, "An InGaAs detector for the 1.01.7- $\mu$ m wavelength range," Applied Physics Letters, vol. 32, p. 446, 1978.

[7] K. Pradeesh, J. J. Baumberg, and G. Vijaya Prakash, "In situ intercalation strategies for device-quality hybrid inorganicorganic self-assembled quantum wells," Applied Physics Letters, vol. 95, no. 3, Article ID 033309, 2009.

[8] I. Saikumar, Shahab Ahmad, J. J. Baumberg, and G. Vijaya Prakash, "Fabrication of excitonic luminescent inorganicorganic hybrid nano- and microcrystals," Scripta Materialia, vol. 67 , no. 10, pp. 834-837, 2012.

[9] Y. Xia, J. A. Rogers, K. E. Paul, and G. M. Whitesides, "Unconventional methods for fabricating and patterning nanostructures," Chemical Reviews, vol. 99, pp. 1823-1848, 1999.

[10] M. Trupke, F. Ramirez-Martinez, E. A. Curtis et al., "Pyramidal micromirrors for microsystems and atom chips," Applied Physics Letters, vol. 88, no. 7, Article ID 071116, 2006.

[11] G. Vijaya Prakash, R. Singh, A. Kumar, and R. K. Mishra, "Fabrication and characterisation of CdSe photonic structures from self-assembled templates," Materials Letters, vol. 60, no. 1314, pp. 1744-1747, 2006.

[12] G. Vijaya Prakash, K. Pradeesh, A. Kumar et al., "Fabrication and optoelectronic characterisation of $\mathrm{ZnO}$ photonic structures," Materials Letters, vol. 62, no. 8-9, pp. 1183-1186, 2008.

[13] R. V. Nair and R. Vijaya, "Three-dimensionally ordered photonic crystal heterostructures with a double photonic stop band," Journal of Applied Physics, vol. 102, Article ID 056102, 3 pages, 2007.

[14] R. V. Nair and R. Vijaya, "Structural and optical characterization of photonic crystals synthesized using the inward growing selfassembling method," Applied Physics A, vol. 90, pp. 559-563, 2008.

[15] M. C. Gonçalves, L. M. Fortes, R. M. Almeida, A. Chiasera, A. Chiappini, and M. Ferrari, "3-D rare earth-doped colloidal photonic crystals," Optical Materials, vol. 31, no. 9, pp. 1315-1318, 2009.

[16] L. Irimpan, V. P. N. Nampoori, P. Radhakrishnan, A. Deepthy, and B. Krishnan, "Size dependent fluorescence spectroscopy of nanocolloids of ZnO," Journal of Applied Physics, vol. 102, no. 6, Article ID 063524, 2007.

[17] S. Coyle, G. Vijaya Prakash, J. J. Baumberg, M. Abdelsalem, and P. N. Bartlet, "Spherical micromirrors from templated selfassembly: polarization rotation on the micron scale," Applied Physics Letters, vol. 83, no. 4, p. 767, 2003.

[18] V. Bulovic, G. Gu, P. E. Burrows, M. E. Thompson, and S. R. Forrest, "Transparent light-emitting devices," Nature, vol. 380, p. 29, 1996.

[19] G. Gu, V. Bulovic, P. E. Burrows, S. R. Forrest, and M. E. Thompson, "Transparent organic light emitting devices," Applied Physics Letters, vol. 68, p. 2606, 1996.

[20] V. Bulović, V. G. Kozlov, V. B. Khalfin, and S. R. Forrest, "Transform-limited, narrow-linewidth lasing action in organic semiconductor microcavities," Science, vol. 279, no. 5350, pp. 553-555, 1998.

[21] V. G. Kozlov, V. Bulović, P. E. Burrows, and S. R. Forrest, "Laser action, in organic semiconductor waveguide and doubleheterostructure devices," Nature, vol. 389, no. 6649, pp. 362364, 1997.

[22] W. Brütting, Ed., Physics of Organic Semiconductors, WileyVCH, Weinheim, Germany, 2005.
[23] M. Furuki, M. Tian, Y. Sato et al., "Observation of sub-100fs optical response from spin-coated films of squarylium dye J aggregates," Applied Physics Letters, vol. 78, no. 18, pp. 26342636, 2001.

[24] K. Misawa, H. Ono, K. Minoshima, and T. Kobayashi, "New fabrication method for highly oriented $J$ aggregates dispersed in polymer films," Applied Physics Letters, vol. 63, no. 5, pp. 577579,1993

[25] F. Sasaki, S. Kobayashi, and S. Haraichi, "Enhancement of the optical nonlinearity in pseudoisocyanine $J$ aggregates embedded in distributed feedback microcavities," Applied Physics Letters, vol. 81, p. 391, 2002.

[26] A. Eilmes, "Excited-state polarizability of J-aggregates," Chemical Physics Letters, vol. 347, no. 1-3, pp. 205-210, 2001.

[27] N. Fukutake, S. Takasaka, and T. Kobayashi, "Energy transfer between two kinds of J-aggregates studied by near-field absorption-fluorescence spectroscopy," Chemical Physics Letters, vol. 361, no. 1-2, pp. 42-48, 2002.

[28] P. Gomez-Romero, "Hybrid organic-inorganic materials-in search of synergic activity," Advanced Materials, vol. 13, no. 3, pp. 163-174, 2001.

[29] E. Fois, A. Gamba, and A. Tilocca, "On the unusual stability of Maya blue paint: molecular dynamics simulations," Microporous and Mesoporous Materials, vol. 57, no. 3, pp. 263-272, 2003.

[30] D. E. Arnold, J. R. Branden, P. R. Williams, G. M. Feinman, and J. P. Brown, "The first direct evidence for the production of Maya Blue: rediscovery of a technology," Antiquity, vol. 82, no. 315, pp. 151-164, 2008.

[31] K. S. Aleksandrov and V. V. Beznosikov, "Hierarchies of perovskite-like crystals," Physics of the Solid State, vol. 39, no. 5, pp. 695-715, 1997.

[32] D. B. Mitzi, "Synthesis, structure, and properties of organicinorganic perovskites and related materials," Progress in Inorganic Chemistry, vol. 48, p. 1, 1999.

[33] D. B. Mitzi, "Organic-inorganic perovskites containing trivalent metal halide layers: the templating influence of the organic cation layer," Inorganic Chemistry, vol. 39, no. 26, pp. 6107-6113, 2000.

[34] A. Poglitsch and D. Weber, "Dynamic disorder in methylammoniumtrihalogenoplumbates (II) observed by millimeter-wave spectroscopy," The Journal of Chemical Physics, vol. 87, no. 11, pp. 6373-6378, 1987.

[35] D. Weber, " $\mathrm{CH}_{3} \mathrm{NH}_{3} \mathrm{PBX}_{3}$, a $\mathrm{Pb}(\mathrm{II})$-system with cubic perovskite structure," Zeitschrift für Naturforschung B, vol. 33, pp. 1443-1445, 1978.

[36] S. Wang, D. B. Mitzi, G. A. Landrum, H. Genin, and R. Hoffmann, "Synthesis and solid state chemistry of $\mathrm{CH}_{3} \mathrm{BiI}_{2}$ : a structure with an extended one-dimensional organometallic framework," Journal of the American Chemical Society, vol. 119, no. 4, pp. 724-732, 1997.

[37] D. B. Mitzi, "Synthesis and crystal structure of the alkylbismuth diiodides: a family of extended one-dimensional organometallic compounds," Inorganic Chemistry, vol. 35, no. 26, pp. 76147619, 1996.

[38] E. O. Schlemper and W. C. Hamilton, "The crystal structure of dimethyltin dilfluoride. An example of octahedral coordination of tin," Inorganic Chemistry, vol. 5, no. 6, pp. 995-998, 1966.

[39] X. Huang, J. Li, and H. Fu, "The first covalent organic-inorganic networks of hybrid chalcogenides: structures that may lead to a new type of quantum wells," Journal of the American Chemical Society, vol. 122, no. 36, pp. 8789-8790, 2000. 
[40] F. Chiarella, R. Mosca, M. Pavesi, A. Zappettini, P. Ferro, and F. Licci, "Enhanced luminescence of $\mathrm{CuCl}$ microcrystals in a organic-inorganic hybrid matrix," Applied Physics A, vol. 88, no. 2, pp. 235-237, 2007.

[41] M. Eraa, K. Miyakea, Y. Yoshidac, and K. Yase, "Orientation of azobenzene chromophore incorporated into metal halidebased layered perovskite having organic-inorganic superlattice structure," Thin Solid Films, vol. 393, pp. 24-27, 2001.

[42] N. F. Stephens, A. M. Z. Slawin, and P. Lightfoot, "A novel scandium fluoride, $\left[\mathrm{C}_{2} \mathrm{~N}_{2} \mathrm{H}_{10}\right]\left(_{0.5}\right)\left[\mathrm{ScF}_{4}\right]$, with an unprecedented tungsten bronze-related layer structure," Chemical Communications, no. 5, pp. 614-615, 2004.

[43] M. Szafrafiski, "Investigation of phase instabilities in guanidinium halogenoplumbates(II)," Thermochimica Acta, vol. 307, no. 2, pp. 177-183, 1997.

[44] R. Kind, "Phase transitions and incommensurability in crystalline model bilayers," Berichte der Bunsengesellschaft für physikalische Chemie, vol. 87, pp. 248-254, 1983.

[45] J. Etxebarria, J. Fernandez, M. A. Arriandiaga, and M. J. Tello, "Influence of the thermal expansion on the piezoelectric photoacoustic detection of ferro-paraelastic phase transition in $\left(\mathrm{CH}_{3} \mathrm{CH}_{2} \mathrm{NH}_{3}\right)_{2} \mathrm{CuCl}_{4}$," Journal of Physics $\mathrm{C}$, vol. 18, no. 1, pp. L13-L17, 1985.

[46] T. Goto, B. Lthi, R. Geick, and K. Strobel, "Elastic soft mode in perovskite-type layer-structure materials," Physical Review B, vol. 22, no. 7, pp. 3452-3458, 1980.

[47] N. Mercier, N. Louvain, and W. Bi, "Structural diversity and retro-crystal engineering analysis of iodometalate hybrids," CrystEngComm, vol. 11, no. 5, pp. 720-734, 2009.

[48] D. B. Mitzi, "Templating and structural engineering in organicinorganic perovskites," Journal of the Chemical Society, Dalton Transactions, no. 1, pp. 1-12, 2001.

[49] D. B. Mitzi, C. D. Dimitrakopoulos, and L. L. Kosbar, "Structurally tailored organic-inorganic perovskites: optical properties and solution-processed channel materials for thin-film transistors," Chemistry of Materials, vol. 13, no. 10, pp. 37283740, 2001.

[50] T. Fujita, H. Nakashima, M. Hirasawa, and T. Ishihara, "Ultrafast photoluminescence from $\left(\mathrm{C}_{6} \mathrm{H}_{5} \mathrm{C}_{2} \mathrm{H}_{4} \mathrm{NH}_{3}\right)_{2} \mathrm{PbI}_{4}$," Journal of Luminescence, vol. 87, pp. 847-849, 2000.

[51] M. Shimizu, J. Fujisawa, and T. Ishihara, "Photoluminescene of the inorganic-organic layered semiconductor $\left(\mathrm{C}_{6} \mathrm{H}_{5} \mathrm{C}_{2} \mathrm{H}_{4}\right.$ $\left.\mathrm{NH}_{3}\right)_{2} \mathrm{PbI}_{4}$ : observation of triexciton formation," Physical Review B, vol. 74, Article ID 155206, 6 pages, 2006.

[52] M. Shimizu, J. I. Fujisawa, and T. Ishihara, "Nonlinear luminescence from an inorganic-organic layered semiconductor," Journal of Luminescence, vol. 122-123, no. 1-2, pp. 485-487, 2007.

[53] T. Ishihara, "Optical properties of PbI-based perovskite structures," Journal of Luminescence, vol. 60-61, pp. 269-274, 1994.

[54] G. A. Mousdis, G. C. Papavassiliou, C. P. Raptopouloub, and A. Terzis, "Preparation and characterization of $\left[\mathrm{H}_{3} \mathrm{~N}\left(\mathrm{CH}_{2}\right)_{6} \mathrm{NH}_{3}\right] \mathrm{PbI}_{4}$ and similar compounds with a layered perovskite structure," Journal of Materials Chemistry, vol. 10, pp. 515-518, 2000.

[55] G. C. Papavassiliou, I. B. Koutselas, A. Terzis, and M. H. Whangbo, "Structural and electronic properties of the natural quantum-well system $\left(\mathrm{C}_{6} \mathrm{H}_{5} \mathrm{CH}_{2} \mathrm{CH}_{2} \mathrm{NH}_{3}\right)_{2} \mathrm{SnI}_{4}$," Solid State Communicationsications, vol. 91, no. 9, pp. 695-698, 1994.

[56] A. Lemmerer and D. G. Billing, "Two packing motifs based upon chains of edge-sharing $\mathrm{PbI}_{6}$ octahedra," Acta Crystallographica Section C, vol. 62, no. 12, p. m597, 2006.
[57] C. P. Raptopoulou, A. Terzis, G. A. Mousdis, and G. C. Papavassiliou, "Preparation, structure and optical properties of $\left[\mathrm{CH}_{3} \mathrm{SC}\left(\mathrm{NH}_{2}\right)_{2}\right]_{3} \mathrm{SnI}_{5},\left[\mathrm{CH}_{3} \mathrm{SC}\left(\mathrm{NH}_{2}\right)_{2}\right]\left[\mathrm{HSC}\left(\mathrm{NH}_{2}\right)_{2}\right] \mathrm{SnBr}_{4}$, $\left(\mathrm{CH}_{3} \mathrm{C}_{5} \mathrm{H}_{4} \mathrm{NCH}_{3}\right) \mathrm{PbBr}_{3}$, and $\left[\mathrm{C}_{6} \mathrm{H}_{5} \mathrm{CH}_{2} \mathrm{SC}\left(\mathrm{NH}_{2}\right)_{2}\right]_{4} \mathrm{~Pb}_{3} \mathrm{I}_{10}$, Zeitschrift für Naturforschung B, vol. 57, pp. 645-650, 2002.

[58] G. C. Papavassiliou, G. A. Mousdis, A. Terzis, and C. P. Raptopoulou, "Crystal structure and optical properties of 4[4-(dimethylamino)-styryl]-1-methyl-pyridinium lead tribromide," Zeitschrift für Naturforschung B, vol. 58, pp. 815-816, 2003.

[59] G. C. Papavassiliou, G. A. Mousdis, I. Koutselas et al., "Some new synthetic low-dimensional semiconductors based on inorganic units," Advanced Materials for Optics and Electronics, vol. 8, no. 5, pp. 263-267, 1998.

[60] C. Xu, S. Fukuta, H. Sakakura et al., "Anomalous electroabsorption in the low-temperature phase of $\left(\mathrm{C}_{10} \mathrm{H}_{21}\right.$ $\left.\mathrm{NH}_{3}\right)_{2} \mathrm{PbI}_{4}$," Solid State Communications, vol. 77, pp. 923926, 1991.

[61] M. Era, S. Morimoto, T. Tsutsui, and S. Saito, "Organicinorganic heterostructure electroluminescent device using a layered perovskite semiconductor $\left(\mathrm{C}_{6} \mathrm{H}_{5} \mathrm{C}_{2} \mathrm{H}_{4} \mathrm{NH}_{3}\right)_{2} \mathrm{PbI}_{4}$, Applied Physics Letters, vol. 65, pp. 676-3, 1994.

[62] K. Morii, M. Ishida, T. Takashima et al., "Encapsulationfree hybrid organic-inorganic light-emitting diodes," Applied Physics Letters, vol. 89, no. 18, Article ID 183510, 3 pages, 2006.

[63] K. Chondroudis and D. B. Mitzi, "Electroluminescence from an organic-inorganic perovskite incorporating a quaterthiophene dye within lead halide perovskite layers," Chemistry of Materials, vol. 11, no. 11, pp. 3028-3030, 1999.

[64] T. Hattori, T. Taira, M. Era, T. Tsutsui, and S. Saito, "Highly efficient electroluminescence from a heterostructure device combined with emissive layered-perovskite and an electrontransporting organic compound," Chemical Physics Letters, vol. 254, pp. 103-108, 1996.

[65] K. Saruwatari, H. Sato, T. Idei et al., "Photoconductive properties of organic-inorganic hybrid films of layered perovskite-type niobate," Journal of Physical Chemistry B, vol. 109, no. 25, pp. 12410-12416, 2005.

[66] W. E. Mahmoud, "A novel photodiode made of hybrid organic/inorganic nanocomposite," Journal of Physics D, vol. 42, no. 15, Article ID 155502, 2009.

[67] A. M. Guloy, Z. Tang, P. B. Miranda, and V. I. Srdanov, "A new luminescent organic-inorganic hybrid compound with large optical nonlinearity," Advanced Materials, vol. 13, pp. 833-837, 2001.

[68] M. Shimizu, J. Fujisawa, and J. Ishi-Hayase, "Influence of the dielectric confinement on excitonic nonlinearity in inorganicorganic layered semiconductors," Physical Review B, vol. 71, no. 20, Article ID 205306, 9 pages, 2005.

[69] M. Shimizu, N. A. Gippius, S. G. Tikhodeev, and T. Ishihara, "Coulomb correction to the dressed exciton in an inorganicorganic layered semiconductor: detuning dependence of the Stark shift," Physical Review B, vol. 69, no. 15, Article ID 155201, 5 pages, 2004.

[70] C. Q. Xu, H. Sakakura, T. Kondo et al., "Magneto-optical effects of excitons in $\left(\mathrm{C}_{10} \mathrm{H}_{21} \mathrm{NH}_{3}\right)_{2} \mathrm{PbI}_{4}$ under high magnetic fields up to 40 T,' Solid State Communicationsications, vol. 79, no. 3, pp. 249-253, 1991.

[71] T. Sekine, T. Okuno, and K. Awaga, "Observation of spontaneous magnetization in the layered perovskite ferromagnet, $(p$ Chloroanilinium $)_{2} \mathrm{CuBr}_{4}$, Inorganic Chemistry, vol. 37, no. 9, pp. 2129-2133, 1998 . 
[72] K. Tanaka, T. Takahashi, T. Kondo et al., "Electronic and excitonic structures of inorganic-organic perovskite-type quantumwell crystal $\left(\mathrm{C}_{4} \mathrm{H}_{9} \mathrm{NH}_{3}\right)_{2} \mathrm{PbBr}_{4}$," Japanese Journal of Applied Physics, vol. 44, no. 8, pp. 5923-5932, 2005.

[73] J. Fujisawa and T. Ishihara, "Excitons and biexcitons bound to a positive ion in a bismuth-doped inorganic-organic layered lead iodide semiconductor," Physical Review B, vol. 70, no. 20, Article ID 205330, 6 pages, 2004.

[74] Y. Kato, D. Ichii, K. Ohashi et al., "Extremely large binding energy of biexcitons in an organic-inorganic quantum-well material $\left(\mathrm{C}_{4} \mathrm{H}_{9} \mathrm{NH}_{3}\right)_{2} \mathrm{PbBr}_{4}$, Solid State Communicationsications, vol. 128, no. 1, pp. 15-18, 2003.

[75] T. Goto, H. Makino, T. Yao et al., "Localization of triplet excitons and biexcitons in the two-dimensional semiconductor $\left(\mathrm{CH}_{3} \mathrm{C}_{6} \mathrm{H}_{4} \mathrm{CH}_{2} \mathrm{NH}_{3}\right)_{2} \mathrm{PbBr}_{4}$," Physical Review $B$, vol. 73 , no. 11, Article ID 115206, pp. 1-5, 2006.

[76] T. Kondo, T. Azuma, T. Yuasa, and R. Ito, "Biexciton lasing in the layered perovskite-type material $\left(\mathrm{C}_{6} \mathrm{H}_{13} \mathrm{NH}_{3}\right)_{2} \mathrm{PbI}_{4}$," Solid State Communicationsications, vol. 105, no. 4, pp. 253-255, 1998.

[77] D. B. Mitzi, K. Chondroudis, and C. R. Kagan, "Organicinorganic electronics," IBM Journal of Research and Development, vol. 45, no. 1, pp. 29-45, 2001.

[78] C. R. Kagan, D. B. Mitzi, and C. D. Dimitrakopoulos, “Organicinorganic hybrid materials as semiconducting channels in thinfilm field-effect transistors," Science, vol. 286, no. 5441, pp. 945947, 1999.

[79] K. Shibuya, M. Koshimizu, Y. Takeoka, and K. Asai, "Scintillation properties of $\left(\mathrm{C}_{6} \mathrm{H}_{13} \mathrm{NH}_{3}\right)_{2} \mathrm{PbI}_{4}$ : exciton luminescence of an organic/inorganic multiple quantum well structure compound induced by $2.0 \mathrm{MeV}$ protons," Nuclear Instruments and Methods in Physics Research B, vol. 194, pp. 207-212, 2002.

[80] D. B. Mitzi, Functional Hybrid Materials, Wiley, Weinheim, Germany, 2004, edited by P. G. Romero and C. Sanchez.

[81] G. Vijaya Prakash, K. Pradeesh, R. Ratnani, K. Saraswat, M. E. Light, and J. J. Baumberg, "Structural and optical studies of local disorder sensitivity in natural organic-inorganic self-assembled semiconductors," Journal of Physics D, vol. 42, no. 18, Article ID 185405, 2009.

[82] V. K. Dwivedi, J. J. Baumberg, and G. Vijaya Prakash, "Direct deposition of inorganic-organic hybrid semiconductors and their template-assisted microstructures," Materials Chemistry and Physics, vol. 137, no. 3, pp. 941-946, 2013.

[83] Y. Kawabata, M. Yoshizawa-Fujita, Y. Takeoka, and M. Rikukawa, "Relationship between structure and optoelectrical properties of organic-inorganic hybrid materials containing fullerene derivatives," Synthetic Metals, vol. 159, no. 9-10, pp. 776-779, 2009.

[84] T. Ishihara, J. Takahanshi, and T. Goto, "Optical properties due to electronic transitions in two-dimensional semiconductors $\left(\mathrm{C}_{n} \mathrm{H}_{2 n+1} \mathrm{NH}_{3}\right)_{2} \mathrm{PbI}_{4}$," Physical Review B, vol. 42, pp. 11099-11107, 1990.

[85] S. Noda, M. Fujita, and T. Asano, "Spontaneous-emission control by photonic crystals and nanocavities," Nature Photonics, vol. 1, no. 8, pp. 449-458, 2007.

[86] D. B. Mitzi, C. A. Feild, W. T. A. Harrison, and A. M. Guloy, "Conducting tin halides with a layered organic-based perovskite structure," Nature, vol. 369, no. 6480, pp. 467-469, 1994.

[87] D. B. Mitzi, S. Wang, C. A. Feild, C. A. Chess, and A. M. Guloy, "Conducting layered organic-inorganic halides containing $\langle 110\rangle$-oriented perovskite sheets," Science, vol. 267, no. 5203, pp. 1473-1476, 1995.
[88] Z. Xu, D. B. Mitzi, C. D. Dimitrakopoulos, and K. R. Maxcy, "Semiconducting perovskites $\left(2-\mathrm{XC}_{6} \mathrm{H}_{4} \mathrm{C}_{2} \mathrm{H}_{4} \mathrm{NH}_{3}\right)_{2} \mathrm{SnI}_{4}(\mathrm{X}=\mathrm{F}$, $\mathrm{Cl}, \mathrm{Br})$ : steric interaction between the organic and inorganic layers," Inorganic Chemistry, vol. 42, pp. 2031-2039, 2003.

[89] D. B. Mitzi, D. R. Medeiros, and P. R. L. Malenfant, "Intercalated organic-inorganic perovskites stabilized by fluoroaryl-aryl interactions," Inorganic Chemistry, vol. 41, no. 8, pp. 2134-2145, 2002.

[90] K. Tanakaa, T. Takahashia, T. Bana, T. Kondoa, K. Uchidab, and N. Miura, "Comparative study on the excitons in lead-halidebased perovskite-type crystals $\mathrm{CH}_{3} \mathrm{NH}_{3} \mathrm{PbBr}_{3} \mathrm{CH}_{3} \mathrm{NH}_{3} \mathrm{PbI}_{3}$," Solid State Communicationsications, vol. 127, p. 619, 2003.

[91] Z. Xu, D. B. Mitzi, and D. R. Medeiros, " $\left[\left(\mathrm{CH}_{3}\right)_{3} \mathrm{NCH}_{2} \mathrm{CH}_{2} \mathrm{NH}_{3}\right] \mathrm{SNI}_{4}$ : a layered perovskite with quaternary/primary ammonium dications and short interlayer iodine-iodine contacts," Inorganic Chemistry, vol. 42, no. 5, pp. 1400-1402, 2003.

[92] A. Lemmerer and D. G. Billing, "P-phenylenediammonium tetraiodozincate(II) dihydrate," Acta Crystallographica Section E, vol. 62, no. 4, pp. m779-m781, 2006.

[93] A. Lemmerer and D. G. Billing, "Two packing motifs based upon chains of edge-sharing $\mathrm{PbI}_{6}$ octahedra," Acta Crystallographica Section C, vol. 62, no. 12, pp. m597-m601, 2006.

[94] H. Krautscheid, C. Lode, F. Vielsack, and H. Vollmer, "Synthesis and crystal structures of iodoplumbate chains, ribbons and rods with new structural types," Journal of the Chemical Society, Dalton Transactions, no. 7, pp. 1099-1104, 2001.

[95] T. Matsui, A. Yamaguchi, Y. Takeoka, M. Rikukawa, and K. Sanui, "Fabrication of two-dimensional layered perovskite $\left[\mathrm{NH}_{3}\left(\mathrm{CH}_{2}\right)_{12} \mathrm{NH}_{3}\right] \mathrm{PbX}_{4}$ thin films using a self-assembly method," Chemical Communications, no. 10, pp. 1094-1095, 2002.

[96] T. Matsushima, K. Fujita, and T. Tsutsui, "High field-effect hole mobility in organic-inorganic hybrid thin films prepared by vacuum vapor deposition technique," Japanese Journal of Applied Physics, vol. 43, pp. L1199-L1201, 2004.

[97] K. Ikegami, "Spectroscopic study of $J$ aggregates of amphiphilic merocyanine dyes formed in their pure Langmuir films," Journal of Chemical Physics, vol. 121, p. 2337, 2004.

[98] D. B. Mitzi, M. T. Prikas, and K. Chondroudis, "Thin film deposition of organic-inorganic hybrid materials using a single source thermal ablation technique," Chemistry of Materials, vol. 11, no. 3, pp. 542-544, 1999.

[99] Z. Y. Cheng, H. F. Wang, Z. W. Quan, C. K. Lin, J. Lin, and Y. C. Han, "Layered organic-inorganic perovskite-type hybrid materials fabricated by spray pyrolysis route," Journal of Crystal Growth, vol. 285, no. 3, pp. 352-357, 2005.

[100] D. B. Mitzi, D. R. Medeiros, and P. W. DeHaven, "Lowtemperature melt processing of organic-inorganic hybrid films," Chemistry of Materials, vol. 14, no. 7, pp. 2839-2841, 2002.

[101] J. E. Gieseking, "The mechanism of cation exchange in the montmorillonite-beidellite-nontronite type of clay minerals," Soil Science, vol. 47, no. 1, pp. 1-14, 1939.

[102] D. M. C. MacEwan, "Identification of the montmorillonite group of minerals by X-rays," Nature, vol. 154, no. 3914, pp. 577578, 1944.

[103] W. F. Bradley, "Molecular associations between montmorillonite and some polyfunctional organic liquids," Journal of the American Chemical Society, vol. 67, no. 6, pp. 975-981, 1945.

[104] E. Ruiz-Hitzky, Functional Hybrid Materials, Wiley, Weinheim, Germany, 2004, edited by P. G. Romero and C. Sanchez. 
[105] T. Ishihara, J. Takahashi, and T. Goto, "Exciton state in twodimensional perovskite semiconductor $\left(\mathrm{C}_{10} \mathrm{H}_{21} \mathrm{NH}_{3}\right)_{2} \mathrm{PbI}_{4}$," Solid State Communicationsications, vol. 69, no. 9, pp. 933-936, 1989.

[106] L. C. Thanh, C. Depeursinge, F. Levy, and E. Mooser, "The band gap excitons in $\mathrm{PbI}_{2}$," Journal of Physics and Chemistry of Solids, vol. 36, no. 7-8, pp. 699-702, 1975.

[107] L. V. Keldysh, "Coulomb interaction in thin semiconductor and semimetal films," Journal of Experimental and Theoretical Physics, vol. 29, p. 658, 1979.

[108] E. Hanamura, N. Nagaosa, M. Kumagai, and T. Takagahara, "Quantum wells with enhanced exciton effects and optical nonlinearity," Materials Science and Engineering B, vol. 1, no. 3-4, pp. 255-258, 1988.

[109] A. Piryatinski, S. A. Ivanov, S. Tretiak, and V. I. Klimov, "Effect of quantum and dielectric confinement on the excitonexciton interaction energy in type II core/shell semiconductor Nanocrystals," Nano Letters, vol. 7, pp. 108-115, 2007.

[110] K. Pradeesh, K. Nageswara Rao, and G. Vijaya Prakash, "Synthesis, structural, thermal and optical studies of inorganic-organic hybrid semiconductors, $\mathrm{R}-\mathrm{PbI}_{4}$," Journal of Applied Physics, vol. 113, no. 8, Article ID 083523, 9 pages, 2013.

[111] M. S. Skolnick, T. A. Fisher, and D. M. Whittaker, "Strong coupling phenomena in quantum microcavity structures," Semiconductor Science and Technology, vol. 13, p. 645, 1998.

[112] K. Pradeesh, J. J. Baumberg, and G. Vijaya Prakash, "Exciton switching and Peierls transitions in hybrid inorganic-organic self-assembled quantum wells," Applied Physics Letters, vol. 2, no. 10, Article ID 173305, 3 pages, 2009.

[113] K. Pradeesh, J. J. Baumberg, and G. Vijaya Prakash, "Strong exciton-photon coupling in inorganic-organic multiple quantum wells embedded low-Q microcavity," Optics Express, vol. 17, no. 24, pp. 22171-22178, 2009.

[114] K. Pradeesh, M. Agarwal, K. K. Rao, and G. Vijaya Prakash, "Synthesis, crystal structure and optical properties of quasione-dimensional lead (II) iodide: $\mathrm{C}_{14} \mathrm{H}_{18} \mathrm{~N}_{2} \mathrm{~Pb}_{2} \mathrm{I}_{6}$," Solid State Sciences, vol. 12, no. 1, pp. 95-98, 2010.

[115] K. Pradeesh, G. S. Yadav, M. Singh, and G. Vijaya Prakash, "Synthesis, structure and optical studies of inorganic-organic hybrid semiconductor, $\mathrm{NH}_{3}\left(\mathrm{CH}_{2}\right)_{12} \mathrm{NH}_{3} \mathrm{PbI}_{4}$," Materials Chemistry and Physics, vol. 124, no. 1, pp. 44-47, 2010.

[116] S. Barman, N. V. Venkataraman, S. Vasudevan, and R. Seshadri, "Phase transitions in the anchored organic bilayers of longchain alkylammonium lead iodides $\left(\mathrm{C}_{n} \mathrm{H}_{2 n+1} \mathrm{NH}_{3}\right)_{2} \mathrm{PbI}_{4} ; n=$ 12, 16, 18," The Journal of Physical Chemistry B, vol. 107, no. 8, pp. 1875-1883, 2003.

[117] K. Gauthron, J. S. Lauret, L. Doyennette et al., "Optical spectroscopy of two-dimensional layered $\left(\mathrm{C}_{6} \mathrm{H}_{5} \mathrm{C}_{2} \mathrm{H}_{4}-\mathrm{NH}_{3}\right)_{2}-\mathrm{PbI}_{4}$ perovskite," Optics Express, vol. 18, no. 6, pp. 5912-5919, 2010.

[118] D. G. Billing and A. Lemmerer, "Synthesis, characterization and phase transitions of the inorganic-organic layered perovskitetype hybrids $\left[\left(\mathrm{C}_{n} \mathrm{H}_{2 n+1} \mathrm{NH}_{3}\right)_{2} \mathrm{PbI}_{4}\right](n=12,14,16$ and 18$)$," New Journal of Chemistry, vol. 32, pp. 1736-1746, 2008.

[119] S. Zhang, G. Lanty, J. S. Lauret, E. Deleporte, P. Audebert, and L. Galmiche, "Synthesis and optical properties of novel organic-inorganic hybrid nanolayer structure semiconductors," Acta Materialia, vol. 57, no. 11, pp. 3301-3309, 2009.

[120] I. Zhitomirsky, L. Gal-Or, A. Kohn, and H. W. Hennicke, "Electrochemical preparation of PbO films," Journal of Materials Science Letters, vol. 14, no. 11, pp. 807-810, 1995.
[121] T. K. Chaudhuri and H. N. Acharya, "Preparation of lead iodide films by iodination of chemically deposited lead sulphide films," Materials Research Bulletin, vol. 17, no. 3, pp. 279-286, 1982.

[122] G. D. Currie, J. Mudar, and O. Risgin, "Photoconductive and photovoltaic spectral response in $\mathrm{Pbl}_{2}$ crystals," Applied Optics, vol. 6, no. 6, pp. 1137-1138, 1967.

[123] A. E. Dugan and H. K. Hknisch, "Defect energy-level structure of $\mathrm{PbI}_{2}$ single crystals," Physical Review, vol. 171, no. 3, pp. 10471051, 1968. 

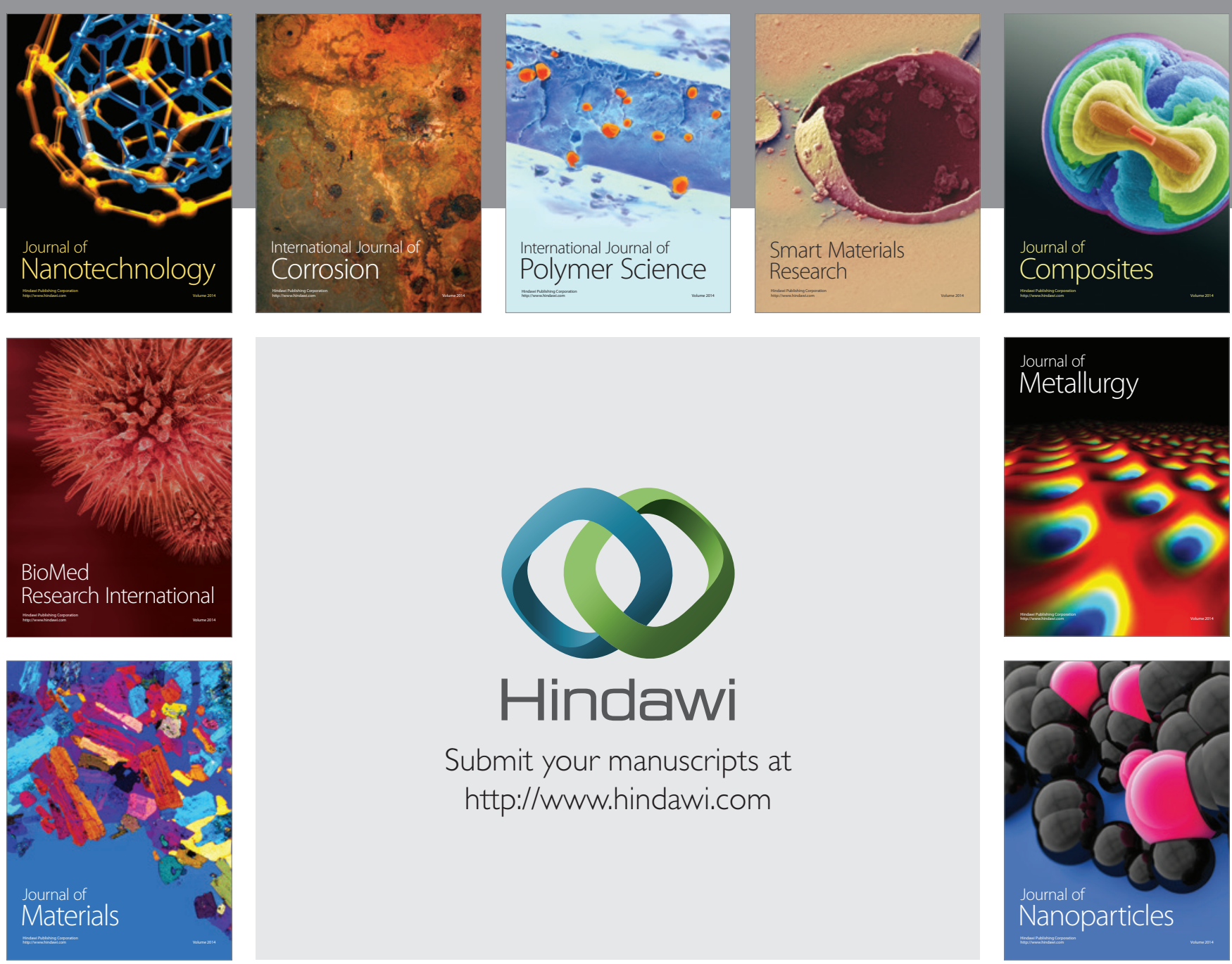

Submit your manuscripts at http://www.hindawi.com
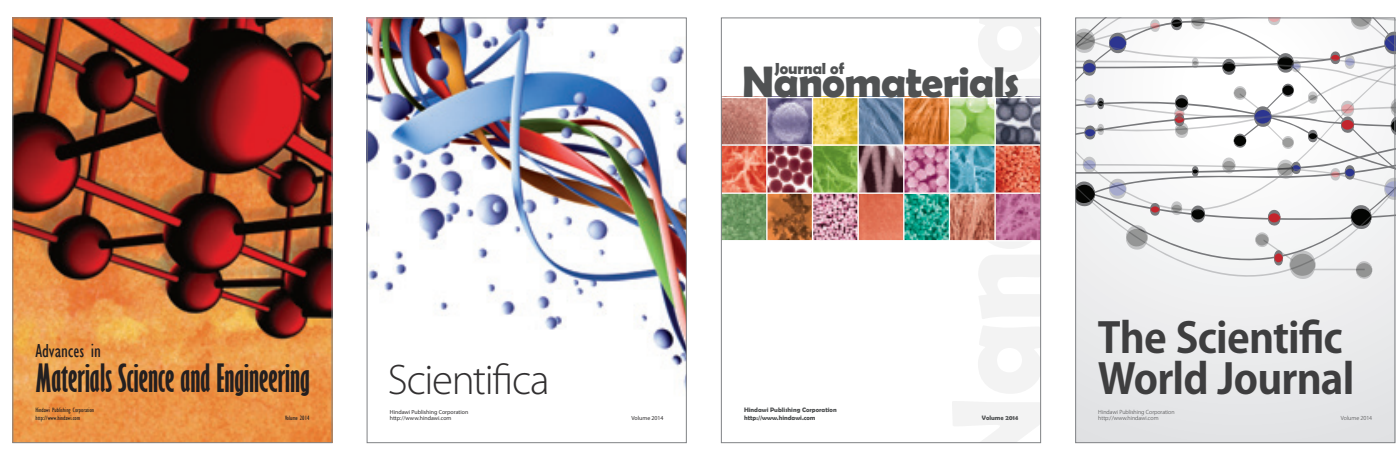

\section{The Scientific World Journal}
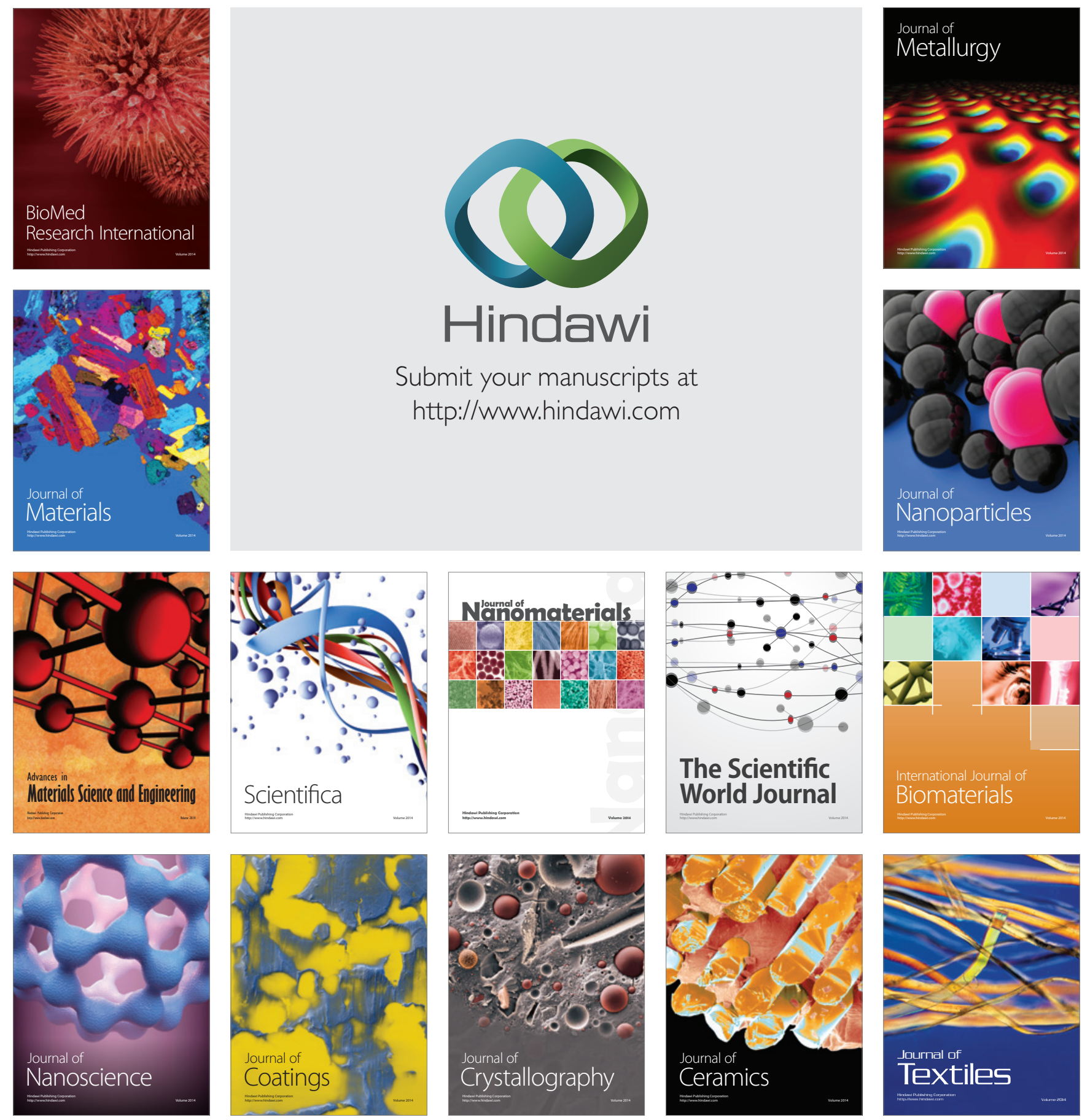